\title{
Push and pull motivations of Brazilian travel lovers
}

\author{
Gisele de Araujo Pereira ${ }^{1, \dagger}$ (10 \\ ${ }^{1}$ Universidade Federal de Minas Gerais, Belo Horizonte, MG, Brazil \\ Marlusa Gosling 2,2(D) \\ ${ }^{2}$ Universidade Federal de Minas Gerais, Belo Horizonte, MG, Brazil
}

\section{ABSTRACT}

Some people are more interested in traveling than others. What factors motivate people to travel? What are the factors that drive them to travel (push motives), and what are those that drive them to choose a certain type of trip (pull motives)? To answer these questions, this study conducted a twophase investigation with Brazilians citizens: an exploratory and qualitative phase with 16 in-depth interviews and a descriptive and quantitative phase based on a model supported by the $3 \mathrm{M}$ Model of Motivation and Personality (Mowen, 2000), and interpreted using structural equation modeling, with partial least squares (PLS). The most important motives identified were push motives (to search for self-knowledge and personal development) and pull motives (to face adventures and challenges, seek novelty, have stories to tell, and experience cultural diversity).

Keywords: Tourism, Travel lover, 3M Model of Motivation and Personality, Consumer Behavior, Push and Pull Motivations.

\section{INTRODUCTION}

Data from the World Tourism Organization (UNWTO, 2016, p.2) show that international tourist arrivals have had virtually uninterrupted growth, "from 25 million in 1950 to 278 million in 1980, 674 million in 2000, and 1186 million in 2015." Estimates also indicate that the growth in international tourists is expected to increase by $3.3 \%$ per year to reach 1.8 billion in 2030 (UNWTO, 2016). Additionally, the share of tourism in emerging economies increased "from 30\% in 1980 to $45 \%$ in 2015 and is expected to reach $57 \%$ by 2030" (UNWTO, 2016, p.3).

Although tourism has significantly grown around the world, this trend is not a global phenomenon. For example, Brazil's numbers cannot be compared with the tourism profiles of the leading countries or other emerging economies like China and South Korea (UNWTO, 2013).

According to the World Economic Forum (2017, p.15):

Brazil is blessed with the largest and most diverse natural resources on the planet (1st). It also has very strong cultural resources (8th), from sports and entertainment to several heritage cultural sites and significant business travel.

Despite its great potential, Brazilian tourism is still sluggish, representing 3.7\% of the national Gross Domestic Product (GDP). Moreover, Brazil holds the $27^{\text {th }}$ position in the travel and tourism competitive index (World Economic Forum, 2017), and doesn't rank among the top-20 countries that expend money on international tourism (UNWTO, 2016).

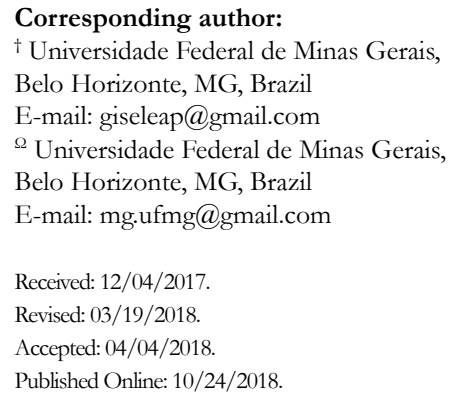


Considering its great tourism potential, which has not been fully exploited, it is important that to investigate tourists' behavior in Brazil, we find ways to promote tourism among Brazilian people. This explains why motivational studies stand out in this research.

Mowen and Minor (2003) argue that motivation is an altered state that leads to behavior directed toward a specific goal. Motivation would then be made up of needs, feelings, and desires that drive people to a certain behavior. According to Caber and Albayrak (2016, p.75), "motivation is the starting point of the consumer decision process and an important construct for understanding tourist behavior," and for this reason it is a recurrent theme in the tourism literature and very important to marketing initiatives (Gazley \& Watling, 2015; Caber \& Albayrak, 2016).

However, as Festinger (1962) shows, cognitive dissonance could affect behavior. When it happens, motivation become a poor predictor of behavior. Therefore, the $3 \mathrm{M}$ Model of Personality and Motivation, also known as Mowen's 3M Model, serves as a relevant tool to examine motivations, personality, and behaviors, as it presents a nomological chain of constructs that indicates how personality influences motivations, which in turn influences the propensity to travel, ultimately influencing travel behavior.

Mowen (2000) used the theory of control adapted from Carver and Scheier (1990) to create the $3 \mathrm{M}$ Model. The theory of control presupposes that behaviors are guided by the discrepancy between the current position in which the individual is and the reference position in which the individual wants to be, thus integrating concepts of personality and motivation (Mowen, 2000). Therefore, motivation is not studied in isolation, but is related to personality traits and behaviors that minimize the effect of cognitive dissonance in the study.

In this regard, the $3 \mathrm{M}$ Model also aggregates personality traits at the analysis. At first glance, motivation and personality could seem technically dissociated; the former could be contextually or emotionally driven, while the latter seems to operate only from the biography of the subject.

However, Montgomery (2008, p. 129) shows that motivation "differs from personality in that it is a deeper and more abstract concept, although similar to it in the sense that motivations are also linked to the social environment and individual traits of the individual." To affirm the same, Mowen (2000) presents the explication of the personality concept used in the 3M Model:

Personality is a hierarchically related set of intra-psychic constructs that reveal consistency across time and that combine with situations to influence the feelings, thoughts, intentions, and behavior of individuals. (Mowen, 2000, p. 2)

Reflecting Mowen's (2000) ideas, Montgomery (2008, p.128) also describes "the combination of social with the individual results to the creation or development of the customer personality." These definitions are broader and imply the combination of personality traits, context, and motivations.

The above shows that motivational processes are intrinsically intertwined with personality traits and they are important elements to put together when trying to relate motivations and behaviors (Mowen, 2000).

Although many theories explain the tourism motivation, this study is based mainly on Crompton's (1979) view of push and pull motives. Gazley and Watling (2015, p.642) explain that "the idea behind this two-dimensional approach is that people travel because they are pushed by their own internal forces and pulled by the external forces of the destination attributes."

The push and pull motives, chosen as the theoretical basis of this study, are completely consistent with the $3 \mathrm{M}$ Model. Besides, the push and pull motives allow us to simplify the classification of motives as internal and external forces that drive travelers, providing a very valuable concept for tourist marketing activities. 
BBR

16,1

65

Basso (2008, p. 24) explains that "the psychological theories of personality indicate that the motivations are the individual responses to the stimuli received and therefore are distinct from person to person." However, most studies seek to identify recurrent motivations between similar profiles with the objective of defining personas with whom it is possible to communicate more effectively. Therefore, even if push and pull are only an approximation of reality, they have often been used for many years by studies around the world and were chosen for this study.

We decided to focus the study in a group of Brazilians who were already closely associated with traveling issues - the kind of people with a propensity to spend money and promote market growth. Accordingly, the study investigates the motivations of people who are strongly involved with trips, called travel lovers in this paper.

Thus, the objective of the present study is to propose and test a model that investigates the relationships between the personality, motivation, and behavior of people who love traveling, supported by the 3M Model of Personality and Motivation and push and pull motivations theory. More specifically, the objectives of this study are to identify 1) the main motivations and relevant compound personality traits of people who love to travel and 2) the most important motivations that drive them to travel (pull) and to choose a specific type of travel (push).

Achieving these objectives, by focusing on the most important motivations of the subjects investigated, is important since it can help marketing professionals and governments to promote tourism growth among travel lovers.

\section{THEORETICAL FRAMEWORK AND HYPOTHESES}

\subsection{Tourism CONSUMer Motivation}

The study of motivation is quite complex since each individual has different reasons for consuming products and services. Past experience, life style, personality, and the image that an individual wants to project may all lead to different consumer motivations. In addition, the behavior process is the result of various "interrelated motives, which can vary from person to person and, over time, even with the same individual" (Dias \& Cassar, 2005, p. 124). Park and Yoon (2009) point that motivational factors are a set of psychological needs that cause a feeling of psychological disequilibrium, which can be balanced again through the action of traveling. Thus, motivation would consist of needs, feelings, and the desires that lead people to manifest certain behaviors (Mowen \& Minor, 2003).

Many studies on tourism motivation take a more general view of the motivations of travelers, as if there was homogeneity of motives. However, we have to consider that different market segments identified by demographics (gender, age, marital status, children, etc.) or psychographics (personality, motivations, values, lifestyle, etc.) and different types of products may cause variations in traveler motivations (Chen \& Sasias, 2014; Galloway et al., 2008, Swarbrooke \& Horner, 2002; Abosag \& Farah, 2014).

Traveler motivations are also influenced by the rules that guide the consumption habits of the era in which they live. Because of that, more recent studies are focusing on understanding the motivations of tourists in specific niches, such as golfers (Kim \& Ritchtie, 2012), cruise travelers (Hung \& Petrick, 2011), adventure tourists (Schneider \& Vogt, 2012), wellness tourists (Voigt, Brown, \& Howat, 2011), and divers (Ong \& Musa, 2012).

Dann (1977) mentions that travel motivations stem from two concepts: anomie and ego exaltation. Anomie would be the desire to "transcend the sense of isolation inherent in everyday life" (Fodness, 1994, p. 556), which "can only be fulfilled if the individual gets away from it all on vacation" (Crompton, 1979, p. 441). The exaltation of the ego stems from the need for recognition, which is obtained through the status conferred by travel. 
The study by Fodness (1994) groups motivations into three main functions: a) the knowledge function, which refers to the attitudes to help people organize what they know and to best understand the world; B) the expression-of-value function, which refers to the attitudes that allow an individual to express their values, divided into ego, self-esteem, and improvement; and c) the adjustment function, which is a recognition of the fact that people strive to minimize pain and maximize reward (pleasure).

As for studies on motivations, one of the most recurrent tourism motivation theories is Crompton's push-pull theory (1979). Abosag and Farah (2014) explain that the push and pull motives can be seen in the perspective by Oliver (1997) that differentiates consumers' needs, wants, and desires. For Oliver (1997, p. 136), "needs are more aligned with deficits, while wants are results from desired enhancements."

Push motivations are determinants of behavior, or internal psychological variables, which motivate a person to travel, such as self-realization, prestige, social interaction, or sense of achievement (Abosag \& Farah, 2016, Gazley \& Watling, 2015; Caber \& Albayrak, 2016). That is, push motives are the very personal needs and desires of each traveler, which lead to a travel demand.

On the other hand, pull motives are external to individuals and determine the behavior; they are situational and are related more to the characteristics of the destination than to the internal needs or personal values of the tourist (Abosag \& Farah, 2016). That is, pull motives are external destination forces or factors attributed to those destinations.

The push motive would explain the desire to travel, while the pull motive would explain the selection of the destination (Crompton, 1979; Lundberg, 1990, Gazley \& Watling, 2015; Caber \& Albayrak, 2016). Push factors relate to intangible issues, inherent to the traveler such as a desire for escape, rest, adventure, or prestige. On the other hand, pull factors relate to the tangible or intangible attractions of the destination (Uysal \& Hagan, 1993, Gazley \& Watling, 2015; Caber \& Albayrak, 2016). Therefore, Galloway (2002) affirms that to analyze travel motivation it is mandatory to specify what are the pull and the push elements and how they are associated.

Several studies used the push and pull approach as motivational factors to understand tourist behavior in different themes, such as events (Lee, Lee, \& Wicks, 2004), senior citizens (Jang \& Wu, 2006), and satisfaction and destination loyalty (Yoon \& Uysal, 2005). Kirkwood (2009) and Chang, Liu, and Chen (2014) explored the push and pull motives in entrepreneurial behavior and migration in virtual social networks.

The objective of this study is to understand the push and pull motives of people who love traveling. This construct, called travel orientation, was considered a strong and continuous affective/cognitive tendency towards active and passive involvement with travel. Although the tourists studied here represent a large population with varied interests and profiles, the group brings together people with an uncommon interest in trips.

Another important theory of tourist motivation is the Travel Career Ladder (TCL) developed by Pearce (1988, 1991, 1993), Pearce and Caltabiano (1983), and Moscardo and Pearce (1986). The theory states that the tourist motivation can occur at five different levels: a) relaxation needs; b) safety requirements; c) relationship needs; d) self-esteem and development needs; and e) the self-actualization and self-fulfillment need. Thus, travelers have a career in which the most inexperienced would turn to the most basic needs and the most experienced to the higher-level needs.

However, one should point out that similar to Maslow's theory, travelers do not move strictly from one level to another that is, some needs can prevail depending on the traveler's career stage.

Pearce and Lee (2005) found results that were a little inconsistent with the TCL theory. The authors found that the most important factors for the most experienced travelers were the joy of experimenting with different cultures and the thrill of having close encounters with nature. As for stimulation, personal development, relationships and security, 
BBR

16,1

67

self-fulfillment, nostalgia, romance, and recognition, they were higher -priority reasons for the less experienced. Motivators such as escape, relaxation, relationship improvement, and self-development were seen as part of the central spine of motivation for all travelers, whether they are more or less experienced.

\subsection{M MODEL}

The Model 3M of Motivation and Personality is a meta-theory, which integrates theories and models derived from the psychology and constructs related to consumer behavior, with the objective of constructing a general and coherent theory about motivation and personality (Mowen, 2000). Since its creation in 2000, the model was used successfully to evaluate the relations between behaviors, personality traits, and motivations in several studies around the world, such as in Pieske (2008), Basso (2008) Avelar (2011), Mowen, Longoria, and Sallee (2009), Sun and Wu (2011), Mowen and Sujan (2005), Fang and Mowen (2009), Scott and Mowen (2007), and Schneider and Vogt (2012).

The 3M Model suggests four levels of personality traits organized hierarchically (Figure 1). The way traits were arranged differs from the other personality models, since it creates a nomological network, which helps to explain the antecedent traits of the behavior studied (Mowen, 2000).

Figure 1 - 3M Model

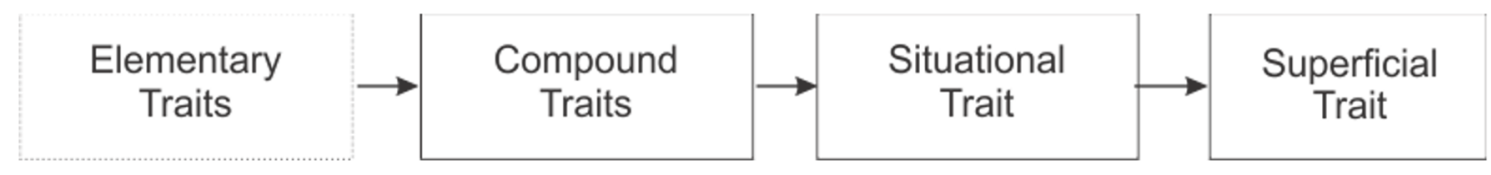

Source: Mowen (2000)

Mowen (2000) explains that the structure of personality traits can be organized according to increasing levels of abstraction, starting from elementary personality traits, which are abstract and comprehensive, to behaviors that can be easily observed. The study by Schneider and Vogt (2012) is a good example to show how the four levels of traits are used.

At the primary level of the Schneider and Vogt (2012) framework are the personality traits indicated by Mowen (2000): openness to experience, conscientiousness, introversion, agreeable, emotional instability, need for body resources, need for material resources, and need for arousal. The elementary traits are related to individual preferences and predispositions due to genetic heritage and what is learnt at the beginning of an individual's life (Mowen, 2000; Monteiro, 2006).

The elementary traits were not evaluated in this study because with the addition of the push and pull motives, the model structure needed to be simplified for reasons of parsimony. Mowen and Sujan (2005) also conducted a study using the 3M Model without including the elementary traits.

This study starts modeling at the level of compound traits, defined as the elementary traits plus the effects of the individual's learned history and cultural environment. Schneider and Vogt (2012) studied the following constructs at the compound level: need for learning, competitiveness, and altruism.

The third level consists of situational traits, which represent the tendency to act in specific behavioral contexts. They are a combination of elementary traits, compound traits, prior learning, and context. Schneider and Vogt (2012) used the following constructs at the situational level: interest in cultural experiences and need for uniqueness. The situational trait used in this study was travel orientation, the main construct of the model. 
At the fourth and last level are superficial traits (e.g., consuming ecological products or the act of travel), which represent long-lasting dispositions to act in specific behavioral ways. Schneider and Vogt (2012) studied the propensity for adventure tourism at the superficial level, which was the focus of their research.

Compound and situational traits are related to the internal behavior motivators, while superficial traits refer to the external motivators or true behavior (Basso, 2008), which this study associates with the act of traveling or with the frequent traveler.

Similar to Mowen and Sujan (2005) and Fang and Mowen (2009), the motives identified in the qualitative phase of this study were added to the personality traits such as push/ situational and pull/superficial motives to form the model studied. The authors explain that these motives can operate at both levels, so the model can be structured and motives incorporated at both the situational and superficial levels, which is what this study's model also followed (Figure 2).

Figure 2 - 3M Model adapted

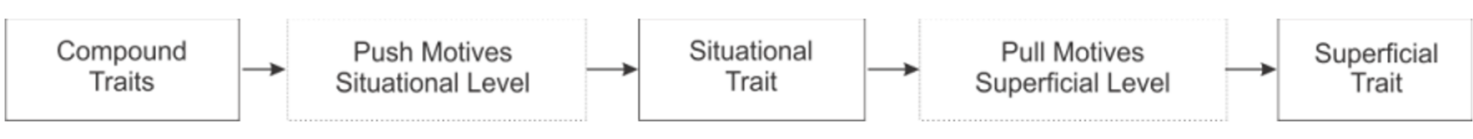

Source: Authors (2015)

\subsection{HYPOTHESIS}

Following these previous studies, push motives are set as situational motives, preceded by compound personality traits and acting as antecedents of travel orientation. Push motives predates the situational trait of travel orientation because they refer to what drives a person to travel, which is an internal motive.

The compound traits in the $3 \mathrm{M}$ Model predate the situational traits, so this study sets them as antecedents of the situational motives, which predate the situational trait of travel orientation. We propose the following hypotheses to evaluate the relationships cited:

There is a positive linear relationship between compound personality traits and push/ situational motives (H1a, H1b, H1c, H1d, H2a, H2b, H2c, H2d, H3a, H3b, H3c, and H3d).

There is a positive linear relationship between push/situational motives and travel orientation (H4a, H4b, H4c, and $\mathrm{H} 4 \mathrm{~d})$.

The motives and the compound traits mentioned in each hypothesis were identified at the qualitative phase and are shown in Table 3.

Pull motives are set as superficial motives and are preceded by travel orientation. They are external motives that affect the act of traveling and determine the kind of trip the person chooses. These are summed up in the following hypotheses:

There is a positive linear relationship between pull/superficial motives and the act of traveling (H5a, H5b, H5c, and H5d).

There is a positive linear relationship between travel orientation and pull/superficial motives (H6a, H6b, H6c, and H6d).

\section{METHODOLOGY}

The study was conducted in two phases. The first phase was exploratory and qualitative, performed through in-depth interviews and supported by content analysis techniques (Bardin, 2009). The findings from the qualitative phase supported the construction of the model and the scales used at the second quantitative phase. The second phase was descriptive and quantitative, performed though a survey application and interpreted using structural equation modeling, with partial least squares (PLS). 
BBR

16,1

69

\subsection{Phase 1 - Qualitative}

Aiming to identify the motivations and compound personality traits of those who love traveling, a qualitative phase was initiated with semi-structured in-depth interviews. The initial cases consisted of three people who said they love traveling and are very much involved with travel issues. Thus, the snowball technique (Malhotra, 2001) was employed, where one interviewee refers to other individuals who also love to travel, and thus the other 13 people were identified. In total, 16 people, with different profiles were interviewed. All of them were from Brazil and were distributed in four different locations: Brasília (Federal District), São Paulo, Minas Gerais, and Rio de Janeiro (Table 1).

Table 1 - Profiles of interviewed people

\begin{tabular}{lcccc}
\hline Interviewee & Age & Gender & Marriage Status & Education/Professional area \\
\hline E1 & 24 & M & Single & Business Administration \\
E2 & 30 & F & Single & Editorial Production \\
E3 & 61 & F & Widow & Social Services \\
E4 & 49 & F & Divorced & Accountancy \\
E5 & 31 & M & Single & Tourism \\
E6 & 24 & M & Single & Communications \\
E7 & 39 & F & Single & Law \\
E8 & 50 & M & Divorced & Electrical engineering, and accountancy and finance \\
E9 & 57 & M & Married & Languages / Finance Management \\
E10 & 28 & F & Single & Marketing and Advertising \\
E11 & 27 & F & Single & Communications and Project Management \\
E12 & 28 & F & Single & Advertising \\
E13 & 26 & F & Single & Marketing and Advertising \\
E14 & 42 & M & Married & Law \\
E15 & 24 & M & Single & Public Relations (Student) \\
E16 & 31 & F & Single & Public Relations \\
\hline
\end{tabular}

Source: Authors (2015)

The number of cases was determined by the saturation point as per Fontanella, Luchesi, Saidel, Ricas, Turato, and Melo (2011) and Fontanella, Ricas and Turato (2008). These authors explain that when answers start becoming very repetitive and similar, without providing anything significantly new, it means the investigation has achieved the saturation point and the sample size is adequate.

The interviews were clearly oriented to a research about people who love traveling; respondents were encouraged to speak as long as they wanted about the issues raised (Table 2). The interviews lasted from 40 to 90 minutes and were conducted between September and December 2015. All the interviews were recorded and transcribed for further analysis.

The analysis was performed using content analysis techniques (Bardin, 2009) with the support of a software named Atlas Ti 5.7.1. In accordance with Bandeira-de-Mello and Cunha (2006), we performed a careful reading of all the interviews to understand the repetitive points and to identify the complete ones for codification and initial categorization. Then, the similarities and differences found in the answers were systematically compared to generate conceptual categories grouped according to selected phrases from the interviews. A numerical analysis of the citations for each category was made, identifying groundedness, which refers to the number of fragments encoded with a certain code. Thus, we were able to identify the most important categories, or those with greater groundedness, to deem them the most recurrent motivators and personality traits in this study. 
Table 2 - Interview questions

1. How did you start to like traveling?

2. Why do you like to travel?

3. Do your closest friends and family travel too?

4. Do you prefer travelling alone or with others? Why?

5. What does travelling mean to you?

6. What kind of place do you prefer to go to?

7. What programs do you enjoy doing when you are traveling?

8. Do you save money to travel? How? Do you cut other expenses?

9. Do you consider travel as one of the priorities of your life? If so, what do you do to ensure this priority?

10. How often do you travel?

11. What was the longest period you've spent traveling without returning home? How was it?

12. How do you choose your tourist destination? What influences you?

13. In everyday life, do you find yourself dreaming/thinking about travel? What are these thoughts?

14. How do you feel when you are traveling? Why?

15. How do you feel when you go home? Why?

16. How do you feel on the eve of a trip? Why?

17. What should a perfect trip have? What cannot happen?

18. How do you feel when you go for a long time without traveling?

19. What do you do to quench your will to travel when you cannot travel?

20. If you could not travel any more, what else would you miss? How could you afford this?

21. Does traveling make you feel free? Why?

22. Do you think the trips that you have done to date have transformed your life? Why and how?

23. Do you live a simpler and more authentic life when you travel? What do you feel about such a life?

24. Do you think you can be more yourself when you travel? Tell me more about.

25. Do you consider yourself a dreamy person? Why?

26. Do you consider travel to be a form of escape? Escape from what?

Source: Authors (2015)

\subsection{Phase 2 - Quantitative}

In the quantitative phase, we distributed an online self-administered survey questionnaire through Facebook, e-mail, and travel discussion forums. A total of 748 individuals from Brazil responded to the questionnaire. The sample size was determined in accordance with the requirement of the analysis techniques suggested by Hair, Black, Babin, Anderson, and Tathan (2009) and Hair, Hult, Ringle, and Sarstedt (2014a).

Since it was not possible to know if the respondent really likes to travel, we used the construct Travel Orientation as a central construct model to filter this issue. This construct enabled the measurement of how much travel-oriented the respondent was, so we were able to use structural equation modeling to evaluate the relation of the Travel Orientation construct with other studied constructs.

As the theoretical and conceptual analyses performed indicated the presence of formative constructs (Hair, Black, Babin, \& Anderson, 2014b), we decided to interpret the data using structural equation modeling with partial least squares. This method was chosen, because PLS is strongly indicated to deal with formative constructs (Hair et al., 2014a). 
BBR

16,1

\section{RESULTS}

\subsection{Phase 1 - Qualitative}

Seven main motivations of travel lovers were identified and classified according to Crompton's (1979) push and pull motives. Four compound personality traits were also identified.

The motives search for self-knowledge and personal development (AUT), search for authenticity and freedom (EUAUT), and break the routine and escape from reality (ROT) were classified as travel orientation antecedents (push). This classification was made because these constructs seemed to point to an internal traveler issue that drives the desire to travel.

These interviewees' comments exemplify push motives:

Search for self-knowledge and personal development (AUT)

Travel alters my behavior, with my way of dealing with the reality here; it increases my ability to tolerate differences, to open my mind about the size of the world, and to value what may be different and people's capacity to build new and better things for the world (E15).

$\mathrm{Ah}$, it is life changing. I think it was as if a paradigm was broken, right? This is what I told you at the beginning, that you think it is very difficult, very complicated to travel, but it is not ... I learnt a lot. ... So, I changed the way I see myself, my attitudes, and priorities (E10).

Search for authenticity and freedom (EUAUT)

I think that if you get rid of some cultural and social issues of your own reality, this inevitably brings you to a higher level of (...); you are going somewhere where most people do not know you, and in a way you are a blank page. (E15)

It is the literal meaning of traveling, my dear; if you do not travel, you are imprisoned. But if you travel, you are free. You are stuck in one place, in just one place, for instance, Belo Horizonte, and you are only in Belo Horizonte! You are imprisoned. You leave Belo Horizonte, and you are free! So if you do not travel, it is like you are in jail. (E11)

Break the routine and escape from reality (ROT)

So I think that travelling is really to escape from this routine, from the beans and rice you eat every day, and trying to live other things. (E2)

On the other hand, the motives experience cultural diversity (DIV), experience adventures and challenges (AVE), seek novelty (NOV), and have stories to tell (HIS) were classified as pull/causes triggered by travel orientation. The reasoning for this classification was that these related more to external issues, allowing for choice in the type of travel and/or choice of destination. The following comments exemplify pull motives:

Experience cultural diversity (DIV)

It is because I like to meet new people, I like to get to know different cultures and different languages. (E16)

I like tourism. If the city I am in has a museum or something like that, I like to visit it, I like to know the local culture, I like to chat with people that live in that region, to know the history of the place. (E2)

I really like to walk in the streets. I like the typical tourist attractions; however I also like to see what is behind those attractions. (E9)

Experience adventures and challenges (AVE)

It is so much fun that in the middle of my trip to China, I went to Vietnam. That was the craziest thing I have ever done in my life, and still I do not know why I did not do more. (E11) 
An experience can turn into a challenge. In China, one thing I wanted very much was to test my limit, that is, to eat something exotic. So, I ate a scorpion in China, which was something I wanted to do. In a way, it also has to do with the capacity to overcome something. (E15)

Seek novelty (NOV)

I think that in my case, there has to be something new. There has to be something that will add value, and for you it is something different, regardless of where you are (E5).

I like to travel, as I like to see different things. I find it an exceptional experience to be in an environment totally different from what I am used to, to see a completely different reality (E11).

Have stories to tell (HIS)

I am alive and I have stories to tell. Otherwise, I do not live just to survive. Something like this: to be proud of my life, I want to have experienced a lot of interesting stuff and therefore I want to live even more interesting stories (E11).

There, I feel the willingness to talk with people I like, people who are close to me, and talking about the trip.... (E9)

Besides the motives, the following compound personality traits are also defined during the qualitative phase: need to learn (NA), self-Efficacy (AUF), need for play (ND), and romanticism (ROM). The first three were already applied by Mowen (2000) in the $3 \mathrm{M}$ Model, and are adapted for this study. The definition of each compound trait/construct is provided in Table 3.

The compound personality trait - romanticism (ROM) - was found at the interviews identified by the subcategories imaginative, dreamer, and curious. That confirms what was found in the literature about romanticism in traveling as seen in Holbrook and Olney (1995). The authors studied romanticism and wanderlust to explore the effect of personality on tourist preferences, dividing the preferences between classicism and romanticism. The authors cite Pirsig (1974, p. 67) contrasting the two concepts:

The romantic way is mostly inspired, imaginative, creative, and intuitive. Feelings rather than facts predominate [...] The classical mode [...] is simple, unadorned, emotionless, economical and carefully proportioned. Its purpose is not to inspire emotionally, but to bring order to chaos [...] People tend to think and feel excessively in one way or another.

The interviewees showed a tendency to be more romantic than classic, because it was set as a construct of the model. The following comments exemplify the romanticism trait:

I need a little magic, a little imagination, and travel can boost that. (E11)

I am very dreamy; sometimes I stop and dream about these things that I would like them to happen to me, right, that they materialized in my life. (E2)

I am Virgo, so that every time I need to check if the lead weights are pinning me to the ground. I dream a lot! (E9)

The constructs/traits travel orientation (TO) and frequent traveler (VF) were also defined according to the qualitative phase that identified five recurrent behaviors among the interviewed: 1) they set travel as a high priority of their lives; 2) they influence other people; 3) they make specific savings and/or commit part of the budget to travel; 4) they value the planning and research phase as a special stage of the journey; 5) they have a great trip (in terms of distance, complexity of planning, and financial investment) at least once a year.

According to the qualitative results, we structured a nomological model, based on Mowen's (2000) and Crompton's (1979) recommendations (push and pull). 


Need to learn (NA)

Self-efficacy (AUF)

Compound traits

Need for play (ND)

Romanticism (ROM)

Travel orientation (TO)

Search for authenticity and freedom (EUAUT)

Search for self-knowledge and personal growth (AUT)

Breaking the routine, escape from reality (ROT)

Seek novelty (NOV)

Experience Cultural Diversity (DIV)

Experience adventures and challenges (AVE)

Have stories to tell (HIS)

Frequent Traveler (VF) Source: Authors (2015)

Type/Level
Situational trait

Push motives (situational level)

Pull motives (superficial level)
The individual's tendency to engage and appreciate significant intellectual challenges.

Capacity and intrinsic motivation to organize and execute the actions required, according to the perceived personal resources.

Tendency to perform hedonistic activities

(diversion, fantasy, excitement, and sensory stimulation) without immediate productive aims.

Tendency to value feelings, dreams, and imagination.

Strong and continuous affective/cognitive tendency towards the active and passive involvement with travel.

To experience freer, simpler and more authentic moments, more connected with one's "true self."

Learning more about oneself, and personal development.

Escaping from common places and the routine, seeking rest, relaxation, and escape from everyday reality.

Getting to know and experience new thin-

Qualitative phase (ad hoc)
Adapted from

Mowen (2000)

and Monteiro

(2006) gs, different from those already familiar with.

Interest in traditions, art forms, celebrations and experiences that reflect the diversity and character of a place and its people.

Experience the unknown, bringing challenges that enrich the experience.

A chance to hear stories and have special experiences that become good stories to tell, reinforcing one's own identity.

Figure 3 - Nomological model

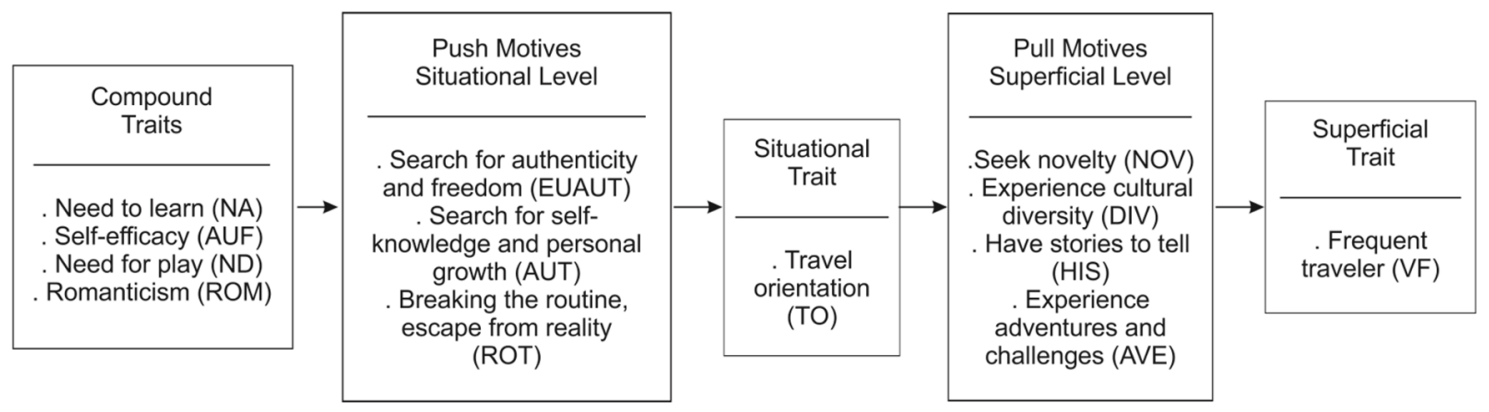


As seen in Figure 3, the model goes from more abstract elements to more concrete behavior. It aggregates the compound traits of personality as the antecedents of push motives, preceding situational travel, which in turn precedes the pull motives that affect superficial traits, that is, concrete behavior (the act of traveling). We evaluated the model in the quantitative phase, as described in the sequence.

\subsection{Phase 2 - Quantitative}

\subsubsection{Respondents' Profiles}

The percentage of women $(70 \%)$ was higher than that of men $(30 \%)$. This is probably because the questionnaire was distributed mainly through Facebook, for which most users in Brazil are women in terms of both number and participation (Gauge, 2014). The age of respondents varied between 15 and 71 years, with an average age of 34 years. With regard to marital status, $51 \%$ were single and $39 \%$ married. All of the respondents had attended college, although some were still studying; thus, $17 \%$ did not yet have a college degree. Of the respondents, $75 \%$, had an income above $2,675 \mathrm{BRL}$ with a maximum of 17,434 BRL. This range represents the three highest income levels in Brazil according to the criteria of the Brazilian Association of Research Enterprises (ABEP, 2014). This is probably because people interested in traveling - by no means a cheap activity - are relatively rich.

\subsubsection{SCALES AND FORMATIVE AND REFLEXIVE CONSTRUCTS}

Based on the results of the qualitative phase and the $3 \mathrm{M}$ Model, we defined 13 constructs for the model. A scale was elaborated using some items adapted from previous studies while some completely new ad hoc ones were created from the findings of the qualitative phase.

We conducted a pilot test to evaluate the scales first, which we monitored with 20 respondents. After the pilot test, the instrument was improved according to the doubts and difficulties expressed by the respondents for each item. We evaluated all the questions (Table 4) by using a 11-point scale that ranged from 0 ("totally disagree") to 10 ("totally agree").

Table 4 - Scale indicators

\begin{tabular}{lcc}
\hline Construct & Indicator & Code \\
\hline \multirow{3}{*}{ Need to learn (NA) } & I enjoy learning new things more than most other people do & NA1Q19 \\
& I greatly value knowledge & NA2Q13 \\
& I have fun getting new knowledge & NA3Q14 \\
& Acquiring new knowledge is essential to my life & NA4Q15 \\
\hline Self-efficacy (AUF) & I like to be in control of the things that happen to me & AUF1Q9 \\
& I can achieve my goals once I make a decision & AUF2Q10 \\
& I am a very determined person & AUF3Q11 \\
Need for play (ND) & I have persistence in achieving my goals & AUF4Q12 \\
\hline & I am a relaxed person & ND1Q1 \\
& I am a playful person & ND2Q2 \\
Romanticism & I like to have fun more than most others do & ND3Q17 \\
(ROM) & I am a dreamer & ROM1Q3 \\
& I am an enthusiastic person & ROM2Q4 \\
& I am an imaginative person & ROM3Q5 \\
\hline
\end{tabular}


BBR

16,1

75
Travel orientation (TO)
A top priority in my life is to travel

I like to travel more than most other people do

The people with whom I relate know that traveling is one of my great passions

Traveling is one of the things I like to do most in life

Traveling is a life purpose to me

My passion for travel influences others

I think about the traveling I will do with all the money I save

\begin{tabular}{l}
\hline $\begin{array}{l}\text { Search for } \\
\text { authenticity } \\
\text { and freedom } \\
\text { (EUAUT) }\end{array}$ \\
\hline $\begin{array}{l}\text { Search for self- } \\
\text { knowledge and } \\
\text { personal growth } \\
\text { (AUT) }\end{array}$ \\
\hline $\begin{array}{l}\text { Breaking the } \\
\text { routine, escape } \\
\text { from reality } \\
\text { (ROT) }\end{array}$
\end{tabular}

When I'm traveling, I care less about what people will think of me

When I'm traveling, I feel freer then ever

Traveling allows me to meet my true self

Traveling leads to personal growth

Traveling increases my self-awareness

Traveling alters my way of dealing with reality at my place of origin

I like to travel to get out of the daily routine

I like to travel because it brings me to another reality

Traveling means rest and an escape from any kind of stress

When I'm travelling, I feel as if I've got a break from real life
TO1Q50

TO2Q39

TO3Q51

TO4Q21

TO5Q22

TO6Q52

TO7Q53

EUAUT1Q27

When I'm traveling, I'm more connected with the real me EUAUT2Q32

EUAUT3Q33

EUAUT4Q34

AUT1Q23

AUT2Q24

AUT3Q25

AUT4Q26

ROT1Q45

ROT2Q46

ROT3Q30

ROT4Q35

I always prefer to travel to places I have never been, instead of going to excellent places that I already know

NOV1Q47

NOV2Q54 experienced.

An ideal travel itinerary has to have new things that I have never seen or

When I am traveling, I very much like to be in an environment completely different from what I am used to.

NOV3Q37

I find it fascinating to get in touch with different cultures while traveling

DIV1Q56

Experiencing cultural diversity while traveling allows me to better understand the differences.

DIV2Q57

Experience cultural diversity (DIV)

When I am travelling, I like to deeply experience the local customs and see how people live.

DIV3Q31

Experiencing cultural diversity expands my view of the world.

DIV4Q58

Experience I like the challenges that travel provides me.

AVE1Q40

adventures and

When I am travelling, I am not afraid to face the unknown.

AVE2Q38

challenges (AVE)

I like to test my limits when I travel.

AVE3Q41

I like to talk about my travels, since it makes me feel important.

HIS1Q44

Have stories to tell (HIS)

I like to talk about my travels, since they are an important part of who I am.

HIS2Q43

I like to be able to talk about the places I have visited and the things I have seen.

HIS3Q42

I travel abroad at least once a year

VF1Q59

I travel out of the city I live in, at least once a year

VF2Q60

Frequent traveler (VF) (An explanatory note clarified that all questions related to leisure trips)

I plan my life to include an annual trip to a place I've always wanted to go

VF3Q62

I plan my life to include an annual trip different from anything I've ever done 
We performed the operationalization of constructs such as reflexive or formative ones by using a theoretical and conceptual evaluation according to Hair et al. (2014b). To validate the reflexive scales, we conducted a unidimensionality analysis using an exploratory factor analysis (EFA), through principal components extraction and varimax rotation (Table 4). The results confirmed the unidimensionality and appropriateness of the technique (KMO $>0.5$, Bartlett $<0.05$, variance extracted $>60 \%$; commonalities $>0.4$ ) for all items, with the exception of item VF1Q59, whose communality and variance were below ideal. Therefore, we excluded the item. We evaluated the scale reliability by using Cronbach's alpha, and all constructs presented acceptable results (>0.7) (Hair, et al., 2014a) (Table 5).

Table 5 - Unidimensionality analysis with reflexive constructs

\begin{tabular}{|c|c|c|c|c|c|c|c|}
\hline Construct & Indicator & Loading & Communality & $\begin{array}{l}\text { variance } \\
\text { Extracted }\end{array}$ & $\mathrm{KMO}$ & Bartlett & Cronbach \\
\hline \multirow{4}{*}{ Self-efficacy (AUF) } & AUF1Q9 & .668 & .447 & \multirow{4}{*}{73.7} & \multirow{4}{*}{0.79} & \multirow{4}{*}{.000} & \multirow{4}{*}{0.876} \\
\hline & AUF2Q10 & .893 & .797 & & & & \\
\hline & AUF3Q11 & .927 & .860 & & & & \\
\hline & AUF4Q12 & .919 & .844 & & & & \\
\hline \multirow{4}{*}{$\begin{array}{l}\text { Search for self-knowledge } \\
\text { and personal growth (AUT) }\end{array}$} & AUT1Q23 & .869 & .755 & \multirow{4}{*}{79.12} & \multirow{4}{*}{0.815} & \multirow{4}{*}{.000} & \multirow{4}{*}{0.912} \\
\hline & AUT2Q24 & .917 & .841 & & & & \\
\hline & AUT3Q25 & .926 & .857 & & & & \\
\hline & AUT4Q26 & .845 & .714 & & & & \\
\hline \multirow{4}{*}{$\begin{array}{l}\text { Search for authenticity and } \\
\text { freedom (EUAUT) }\end{array}$} & EUAUT1Q27 & .845 & .714 & \multirow{4}{*}{72.09} & \multirow{4}{*}{0.779} & \multirow{4}{*}{.000} & \multirow{4}{*}{0.871} \\
\hline & EUAUT2Q32 & .837 & .700 & & & & \\
\hline & EUAUT3Q33 & .829 & .688 & & & & \\
\hline & EUAUT4Q34 & .884 & .782 & & & & \\
\hline \multirow{4}{*}{ Need to learn (NA) } & NA1Q19 & .769 & .591 & \multirow{4}{*}{79.6} & \multirow{4}{*}{0.824} & \multirow{4}{*}{.000} & \multirow{4}{*}{0.913} \\
\hline & NA2Q13 & .928 & .861 & & & & \\
\hline & NA3Q14 & .936 & .877 & & & & \\
\hline & NA4Q15 & .926 & .857 & & & & \\
\hline \multirow{3}{*}{ Need for play (ND) } & ND1Q1 & .914 & .835 & \multirow{3}{*}{73.6} & \multirow{3}{*}{0.641} & \multirow{3}{*}{.000} & \multirow{3}{*}{0.817} \\
\hline & ND2Q2 & .913 & .833 & & & & \\
\hline & ND3Q17 & .736 & .542 & & & & \\
\hline \multirow{4}{*}{ Romanticism (ROM) } & ROM1Q3 & .846 & .715 & \multirow{4}{*}{70.4} & \multirow{4}{*}{0.815} & & \\
\hline & ROM2Q4 & .875 & .765 & & & 000 & 050 \\
\hline & ROM3Q5 & .834 & .696 & & & .000 & 0.859 \\
\hline & ROM4Q16 & .800 & .640 & & & & \\
\hline & ROT1Q45 & .838 & .703 & & & & \\
\hline Breaking the routine. escape & ROT2Q46 & .825 & .681 & 6567 & 0746 & $0 \cap 0$ & 0825 \\
\hline from reality (ROT) & ROT3Q30 & .780 & .609 & 65.67 & 0.746 & .000 & 0.825 \\
\hline & ROT4Q35 & .797 & .635 & & & & \\
\hline & VF1Q59* & .618 & .382 & & & & \\
\hline & VF2Q60 & .672 & .452 & & & & \\
\hline & VF3Q62 & .793 & .630 & & & & \\
\hline Frequent traveler (VF) & VF4Q61 & .823 & .677 & 58.93 & 0.884 & .000 & 0.881 \\
\hline & VF5Q63 & .836 & .699 & & & & \\
\hline & VF6Q64 & .802 & .643 & & & & \\
\hline & VF7Q65 & .802 & .643 & & & & \\
\hline
\end{tabular}


BBR

16,1

\begin{tabular}{lcccccccc}
\hline & TO1Q50 & .912 & .832 & & & & \\
& TO2Q39 & .840 & .706 & & & & \\
& TO3Q51 & .915 & .838 & & & & \\
Travel orientation (TO) & TO4Q21 & .854 & .729 & 75.5 & 0.928 & .000 & 0.946 \\
& TO5Q22 & .887 & .787 & & & & \\
& TO6Q52 & .861 & .741 & & & & \\
& TO7Q53 & .807 & .652 & & & & \\
\hline Parameter & & $>0.4$ & $>0.4$ & $>60 \%$ & $>0.5$ & $<0.05$ & $>0.7$
\end{tabular}

*After VF1Q59 was excluded, the extracted variance increased to $63.44 \%$

Source: Authors (2015)

\subsubsection{Outliters, Normality, And Linearity}

Among all 748 responses collected, we found 16 outliers. These were excluded, since they formed only a small percentage $(2 \%)$ of the data. Thus, 732 valid responses remained. To assess normality, we applied the Kolmogorov-Smirnov test. All $p$ values were $<0.005$, confirming the non-normality. The Spearman's test applied to assess linearity presented a significant $1 \%$ two-tail correlation, indicating linearity.

\subsubsection{Reflexive And Formative Measurement Model}

The hypothetical model (Figure 4) shows a completely sequenced structure; that is, all constructs of one level are linked to the next. Figure 3 also shows which construct was operationalized as formative (arrows pointing to the circle - AVE, DIV, HIS, and NOV) and reflexive (arrows pointing from the circle - all the other constructs).

Figure 4 - Hypothetical model

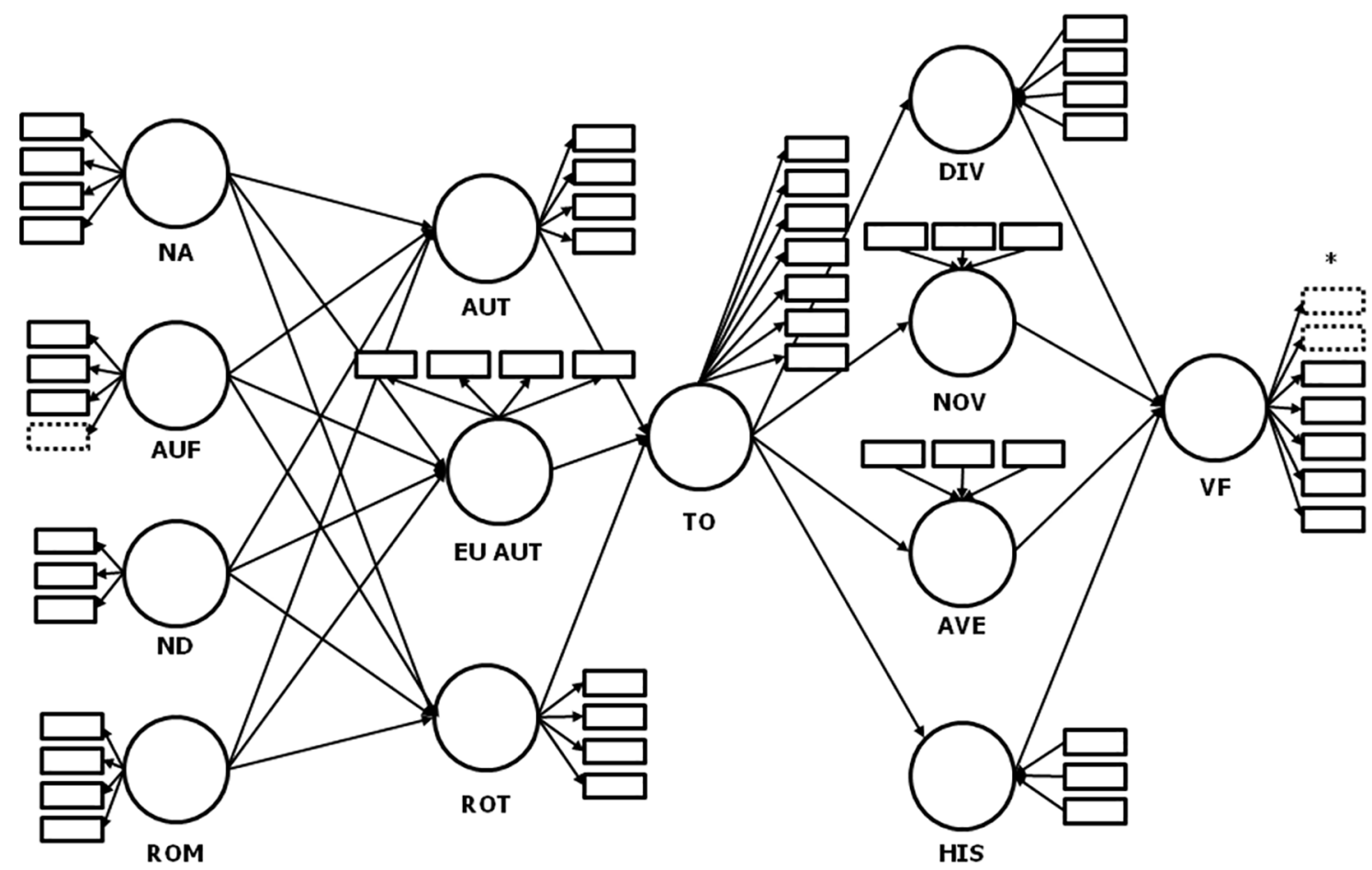

Dashed items were excluded during the analysis.

Source: Authors (2015). 
We evaluated the reflexive measurement model using compound reliability tests, a reliability indicator assessment (outer loadings), and convergent and discriminant validity analyses. All the constructs showed compound reliabilities above 0.7, and AVE (average variance extracted) above 0.5 , indicating that convergent reliability and validity findings were within the parameters. With regard to the reliability indicator, two items presented factor loadings below the expected parameters (0.708 - Hair et al., 2014b): AUF1Q9 (0.704), and VF2Q60 (0.673). Excluding indicators with low loadings resulted in an increased compound reliability and AVE; thereby, justifying the procedure (Hair et al., 2014b).

Specific formative constructs needed different measures: convergent validity, collinearity between indicators, convergent validity, and significance and relevance. All the analyses were conducted according to the parameters indicated by Hair et al. (2014b).

\subsubsection{Evaluation of the Structural Model}

Evaluation of the outer model consisted of the following measures: 1) collinearities; 2) path coefficients (beta weight), which indicate the strength of the relationship between the two constructs; 3) t values, which evaluate the significance of the relationships; 4) coefficient of determination $\mathrm{R}^{2}$, which represents the amount of explained variance of the endogenous constructs; 5) the effect size $\mathrm{f}^{2}$, which measures how much an independent construct contributes to the $\mathrm{R}^{2}$ of the dependent construct. Table 6 shows the parameters of the measures:

Table 6 - Evaluation parameters

\begin{tabular}{lc}
\hline Measure & Parameters \\
\hline Collinearity among the indicators & $>0.2<5$ \\
\hline & $>=0.25$ weak \\
$\mathrm{R}^{2}$ & $>=0.5$ moderate \\
& $>=0.75$ substantial \\
\hline & $>=2.57$ significance at $1 \%$ \\
$\mathrm{t}$ value & $>=1.96$ significance at $5 \%$ \\
& $>=1.65$ significance at $10 \%$ \\
$\mathrm{f}^{2}$ & $>=0.02$ small \\
& $>=0.15$ medium \\
\hline
\end{tabular}

Source: Based on Hair et al. (2014)

We did not find any problems of collinearity among the constructs of the model. Table 7 shows the values of $\mathrm{R}^{2}$, the test indicating whether each hypothesis was supported, as well as the size of the effect.

Only H1a and $\mathrm{H} 2 \mathrm{a}$ were not confirmed, indicating that no relationships were found between the personality trait self-efficacy (AUF) and the push motives search for authenticity and freedom (EUAUT) and search for self-knowledge and personal development (AUT). Although all the other hypotheses were confirmed, only five (H4b, H6a, H6b, H6c, and H6d) had an effect size, $\mathrm{f}^{2}$, between large and medium, indicating that the independent construct affected the dependent construct in a relevant manner.

$\mathrm{H} 2 \mathrm{~b}, \mathrm{H} 2 \mathrm{~d}, \mathrm{H} 3 \mathrm{a}, \mathrm{H} 3 \mathrm{~b}, \mathrm{H} 3 \mathrm{~d}, \mathrm{H} 4 \mathrm{c}$, and $\mathrm{H} 5 \mathrm{~b}$ presented $\mathrm{f}^{2}$ values below the indicated parameters, showing that although the relationships were significant, the independent constructs alone did not show a relevant impact on the dependent constructs.

Regarding the explanatory potential of the antecedent constructs for the consequents $\left(\mathrm{R}^{2}\right)$, the explanatory capacity for the construct travel orientation $(\mathrm{TO})$ was moderate $(55 \%)$ 
Table 7 - Evaluation of the structural model

\begin{tabular}{|c|c|c|c|c|c|c|c|c|}
\hline & & $\mathrm{R}^{2}$ & t value & Significance & Support & Path & $\mathrm{f}^{2}$ & Effect size $\mathrm{f}^{2}$ \\
\hline H1a & AUF $>$ EUAUT & \multirow{4}{*}{0.369} & 0.155 & NS & No & -0.007 & 0.000 & NA \\
\hline $\mathrm{H} 1 \mathrm{~b}$ & NA > EUAUT & & 5.558 & $1 \%$ & Yes & 0.251 & 0.041 & Small \\
\hline $\mathrm{H} 1 \mathrm{c}$ & ROM $>$ EUAUT & & 5.047 & $1 \%$ & Yes & 0.260 & 0.035 & Small \\
\hline H1d & ND $>$ EUAUT & & 3.839 & $1 \%$ & Yes & 0.180 & 0.027 & Small \\
\hline $\mathrm{H} 2 \mathrm{a}$ & AUF $>$ AUT & \multirow{4}{*}{0.483} & 0.043 & NS & No & 0.002 & 0.000 & NA \\
\hline $\mathrm{H} 2 \mathrm{~b}$ & $\mathrm{ND}>\mathrm{AUT}$ & & 2.109 & $5 \%$ & Yes & 0.091 & 0.008 & $\mathrm{AB}$ \\
\hline $\mathrm{H} 2 \mathrm{c}$ & ROM $>$ AUT & & 5.730 & $1 \%$ & Yes & 0.346 & 0.076 & Small \\
\hline $\mathrm{H} 2 \mathrm{~d}$ & NA>AUT & & 6.320 & $1 \%$ & Yes & 0.328 & 0.084 & Small \\
\hline $\mathrm{H} 3 \mathrm{a}$ & AUF $>$ ROT & \multirow{4}{*}{0.353} & 2.157 & $5 \%$ & Yes & 0.098 & 0.009 & $\mathrm{AB}$ \\
\hline $\mathrm{H} 3 \mathrm{~b}$ & $\mathrm{NA}>\mathrm{ROT}$ & & 2.685 & $1 \%$ & Yes & 0.148 & 0.014 & $\mathrm{AB}$ \\
\hline $\mathrm{H} 3 \mathrm{c}$ & $\mathrm{ND}>\mathrm{ROT}$ & & 2.782 & $1 \%$ & Yes & 0.118 & 0.011 & $\mathrm{AB}$ \\
\hline $\mathrm{H} 3 \mathrm{~d}$ & $\mathrm{ROM}>\mathrm{ROT}$ & & 5.558 & $1 \%$ & Yes & 0.321 & 0.052 & Small \\
\hline $\mathrm{H} 4 \mathrm{a}$ & EUAUT > TO & & 2.837 & $1 \%$ & Yes & 0.144 & 0.016 & $\mathrm{AB}$ \\
\hline $\mathrm{H} 4 \mathrm{~b}$ & AUT > TO & & 11.486 & $1 \%$ & Yes & 0.579 & 0.246 & Medium \\
\hline $\mathrm{H} 4 \mathrm{c}$ & $\mathrm{ROT}>\mathrm{TO}$ & & 1.688 & $10 \%$ & Yes & 0.063 & 0.005 & $\mathrm{AB}$ \\
\hline H5a & $\mathrm{NOV}>\mathrm{VF}$ & \multirow{4}{*}{0.355} & 4.423 & $1 \%$ & Yes & 0.199 & 0.028 & Small \\
\hline $\mathrm{H} 5 \mathrm{~b}$ & $\mathrm{DIV}>\mathrm{VF}$ & & 2.325 & $5 \%$ & Yes & 0.108 & 0.009 & $\mathrm{AB}$ \\
\hline $\mathrm{H} 5 \mathrm{c}$ & $\mathrm{HIS}>\mathrm{VF}$ & & 3.855 & $1 \%$ & Yes & 0.188 & 0.031 & Small \\
\hline $\mathrm{H} 5 \mathrm{~d}$ & $\mathrm{AVE}>\mathrm{VF}$ & & 4.452 & $1 \%$ & Yes & 0.213 & 0.032 & Small \\
\hline H6a & $\mathrm{TO}>\mathrm{NOV}$ & 0.427 & 24.367 & $1 \%$ & Yes & 0.654 & 0.746 & Large \\
\hline H6b & $\mathrm{TO}>\mathrm{DIV}$ & 0.396 & 21.622 & $1 \%$ & Yes & 0.629 & 0.655 & Large \\
\hline H6c & $\mathrm{TO}>\mathrm{HIS}$ & 0.456 & 24.988 & $1 \%$ & Yes & 0.675 & 0.838 & Large \\
\hline H6d & $\mathrm{TO}>\mathrm{AVE}$ & 0.492 & 27.347 & $1 \%$ & Yes & 0.701 & 0.969 & Large \\
\hline
\end{tabular}

NS - Non-significant

NA - It does not apply, as it is non-significant

$\mathrm{AB}$ - Below the recommended parameters; although significant, the effect is small.

Source: Study Data (2015)

and frequent traveler (VF) low (36\%). Hair et al. (2014b) suggest that $20 \%$ is an acceptable number for exploratory studies on consumer behavior. These results, although lower than those found by Monteiro (2006) for compulsive shopping (84.3\%) and fashion habits (66.6\%), were close to the average (44\%) reported by Mowen (2000) with the 3M Model.

Regarding the formative constructs, we were able to identify one with the greatest effect on the construct frequent traveler (VF), through the evaluation of total effects (NOV > VF: 0.199, DIV > VF: 0.108, HIS > VF: 0.188, AVE > VF: 0.213). The construct experience adventures and challenges (AVE) had the greatest impact on the VF construct.

It was also possible to identify the contribution of each indicator included in the construct by assessing the outer weights. The most important indicators are AVE1Q40 - "I like the challenges that travel provides me" $(0.850)$; DIV3Q31 - "When I am travelling, I like to deeply experience the local customs and see how people live" (0.577); HIS2Q43 - "I like to talk about my travels, since they are an important part of who I am" (0.723); and NOV3Q37 - "When I am travelling, I very much like to be in an environment completely different from what I am used to (0.614). 


\section{DISCUSSION}

The first specific objective of this research was to understand what are the main motivations and relevant compound personality traits of people who love to travel. It was performed at the qualitative phase, which identified the following push motives, or travel orientation antecedents: search for self-knowledge and personal development (AUT), search for authenticity and freedom (EUAUT), and break the routine and escape from reality (ROT). In addition, the following pull motives, or travel orientation consequents, were found: experience cultural diversity (DIV), experience adventures and challenges (AVE), seek novelty (NOV), and have stories to tell (HIS). Besides these motives, the following compound personality traits were also identified: need to learn (NA), self-efficacy (AUF), need for play (ND), romanticism (ROM).

The second specific objective was to identify the most important motivations and personality traits of travel lovers that prompt them to travel (pull) and the factors that guide their choice of travel type (push). This was accomplished by proposing and testing the model studied, which was supported by the findings of the qualitative phase.

Since we have already presented the first objective along with the qualitative phase results, we only discuss the second objective here. From the data analysis the results can be divided into two categories: those that contribute to a better understanding of the motivation and personality of people who love traveling, and therefore deserve great attention; those without much contribution to research, and therefore deserve little attention.

The four pull motives - experience adventures and challenges (AVE), seek novelty (NOV), have stories to tell (HIS), and experience cultural diversity (DIV) - are constructs that deserve great attention. The first three pull motives present great importance both as antecedents of the act of traveling (VF) and as consequents of travel orientation. The last one, experience cultural diversity (DIV), is not as relevant as the others and will be discussed later.

As literature shows pull motives are more external or tangibles, this means they determine the choice of travel type or place to go, making people think about "how the trip should be?. Pull motives are related to the choice of how the trip will be, not about the desire to travel. What determines the desire to travel are push motives, shown later.

This study indicates that the more travel orientation one has, the more propitious they are to seek the three pull motivations - experience adventures and challenges (AVE), seek novelty (NOV) and have stories to tell (HIS). The results about these pull motives are unraveled in sequence.

Special attention should be given to the pull motive experience adventures and challenges (AVE) and the statement "I like the challenges that travel provides me"," which indicates the importance respondents attach to the adventures and challenges during travel. Several studies (Swarbrooke, Beard, Leckie, \& Pomfret, 2011; Uysal \& Hagan; 1993; Swarbrooke \& Horner; 2002; Plog, 1987; Schneider \& Vogt, 2012) also cite the search for adventure as a motivator in tourism.

The pull motive have stories to tell (HIS), followed by the statement "I like to talk about my trips, since they are an important part of who I am", which also deserves great attention as the second-most important determinant of the act of traveling (VF), which is in turn influenced by travel orientation (TO). Correia, Valle, and Moço (2005), studying the motivations and perceptions of Portuguese tourists, identified three main factors: knowledge, leisure, and socialization. Within socialization, one of the elements studied was the fact of "talking about traveling with friends," which corroborates the issue identified here about the sharing of travel experiences. In addition, Dann (1977) mentions exaltation of the ego, which derives from the need for recognition obtained through the status conferred by travel. 
BBR

16,1

81

Other research confirms that having a story to tell is an important motivation for Brazilians and shows that $42 \%$ of the content of one of the largest social networks in the world, Facebook, relates to travel (SKIFT, 2015). Radius Kommunikation (2016) finds that Brazilians are champions in posting their travel experiences on Facebook.

Seek novelty (NOV) was the third-most important pull motive, followed by the statement "When I am traveling I very much like to be in a completely different environment from what I am used to." This search for the new is consistent with the idea of experiential loyalty, quoted by Mckercher, Denizci-Guillet, and Ng (2012), which assumes that the so-called "new tourists" are not committed to a specific tourist destination but play with the possibility of having new experiences with each trip or similar experiences in places not yet visited.

However, the pull motive experience cultural diversity (DIV) lacked sufficient relevant data, unlike the other three pull motives. However, the lack of relevance of the DIV construct deserves further investigation since the search for cultural diversity is often cited in the literature on motivation in tourism (Swarbrooke \& Horner, 2002; Pearce \& Lee, 2005), and the statement "When I am traveling, I like to deeply experience the local habits and see how people live" was very well scored.

Having mentioned push motives, it is important to remember that they are more related to internal issues, which means they drive the desire to travel. It is not necessarily related to the kind of trip as pull motives, but about what leads them to travel: "what I travel for".

The results indicated that someone who is very attached to travel matters is likely to be impacted by marketing activities that promise tourism activities. They promote self-knowledge, personal development, search for authenticity and freedom. For a better understanding of the results about push motives, we unravel it in the sequence.

The push motive breaking the routine and escape from reality (ROT), is included in the category deserving great attention; therefore, its results, though weak, provide some information about travel lovers. The results show that breaking the routine may not be an important element among travel lovers. Being more experienced travelers, they may not see breaking the routine as a motive driving them to travel. Thus, breaking the routine would be at a more elementary level of motivation (facing the most basic needs). However, the travel lover may seek motives more oriented to self-realization. Dividing the sample into clusters representing different stages of the traveler's careers (Pearce, 1988, 1991, 1993) that could provide more insight.

The push motive search for self-knowledge and personal development (AUT) also deserves great attention considering that it was the push motive with better predictive relationship with travel orientation (TO). It refers to learning focused on self-discovery - knowing who one is - with its characteristic limitations and traits. According to Middleton (2001, p. 78), "for centuries travel has been associated with a widening of consciousness and self-development through knowledge and exposure to other cultures and human circumstances, [...] [and] holidays and associations with rest and leisure have always had a stimulating effect on people's minds and are clearly linked to self-development."

Considering that people who love to travel are relatively experienced tourists, their motives would expectedly relate to the higher levels of the travelers' career ladder (Pearce, 1988, 1991, 1993, Pearce \& Caltabiano, 1983; Moscardo \& Pearce, 1986; Pearce and Lee; 2005). The higher levels comprise the following elements: 1) self-esteem and development needs; 2) the need for self-update and self-fulfillment (Pearce, 1988, 1991, 1993), 3) experimenting with different cultures (Pearce \& Lee, 2005), and 4) being close to nature (Pearce \& Lee, 2005). The first three elements are completely related to what is found in this study - experience adventures and challenges (AVE), seek novelty (NOV), have stories to tell (HIS), experience cultural diversity (DIV), and search for self-knowledge and 
personal development (AUT). All the identified motivations can be related to two groups of motivations. Only the last element, being close to nature, was not found in this research.

Avelar (2011) states that consumers respond to both rational (utilitarian - functional and practical) and emotional (hedonistic - subjective and emotional benefits) motivations and that each person establishes their motivations in a certain way. This study found a greater number of emotional motivations, probably because consumer behavior in tourism has a much greater emotional load than other activities, as mentioned by Dias and Cassar (2005), Fodness (1994), and Swarbrooke and Horner (2002).

Gazley and Watling (2015) found that pull factors affect consuming experiences, but not consuming products. The authors suggest that "this may be because pull factors are very much related to the idea of being a traveler rather than being a tourist" (p.651). What this means is that travelers are more experienced than tourists in traveling activities. This explains why this study found more emotional than rational motives among those who love to travel - experienced travelers who value experiences more than goods.

The compound personality traits need for play (ND), need to learn (NA), and romanticism (ROM) and the push motive search for authenticity and freedom (EUAUT) had an impact on the model, though not a very strong one. Moreover, the compound personality trait self-efficacy (AUF) had no relevant impact on the model. Therefore, these results cannot be considered significant for this research. However, weak results are obtained probably because the elementary traits were not used in the model as suggested by Mowen (2000) for the 3M Model applications. Thus, we cannot affirm whether the four personality traits identified at the qualitative phase or the push motive search for authenticity and freedom (EUAUT) are really associated with travel lovers, deserving further investigation.

\section{FINAL CONSIDERATIONS}

\subsection{Practical Contributions}

The consumers studied, namely, those who really like to travel even if they may have different interests, have a great propensity to acquire more tourist products, services, and experiences than other tourists. Thus, those in the Brazilian tourism business can benefit from the findings of this research and use these to develop products and services that are more consistent with the motivations identified herein.

The division of motivations such as push and pull was carried out with the aim of better understanding what stimulates people who love to travel, looking at the internal and more intangible (push) and external and more tangible (pull) sides. Therefore, marketers can better direct their efforts either to arouse in people the desire to travel, or to direct the choice of place and/or type of trip.

To clarify how we classified the push and pull motives, it is important to remember that push motives are presented as internal an intangible once they relate more to personal questions or travelers' desires (self-knowledge and personal development (AUT), search for authenticity and freedom (EUAUT), and break the routine and escape from reality (ROT)). Moreover, pull motives are cited as external and tangible because they relate to what the locality or kind of trip can offer to travelers (experience cultural diversity (DIV), experience adventures and challenges (AVE), seek novelty (NOV), and have stories to tell (HIS)).

Related to the pull motives that influence the choice of the place to go or the kind of trip, it is relevant to highlight the have stories to tell (HIS) motive. Lindstrom (2012) sees an advantage in using the promotion of stories as important elements in building a strong brand. Thus, tourism companies could promote a story exchange among their customers as a way to attract travel lovers' attention, allowing them to promote their own personal experiences and inspiring them to go to a specific place or learn about a specific type of trip. 
Yet relating to the pull motives, the highlighted statements "When I am travelling, I like to deeply experience the local habits and see how people live" and "When I am travelling I very much like to be in a completely different environment from what I am used to" provide points of reference for the development of tourism services, focusing on promoting a relationship with the local public and the creation of differentiated spaces such as hotels and theme parks.

The pull motive with the highest indices was searching for adventures and challenges (AVE). Therefore, marketing professionals should invest in products and services that meet this need. In addition, it could be interpreted that since travel lovers appear to appreciate the challenges that travel provides, they may prefer to travel independently, rather than in organized excursions.

Relating to the push motives, searching for self-knowledge and personal development (AUT) can be exploited by tourism professionals through the creation of products and services that appeal to self-knowledge arousing in people the desire to travel: offering travel accompanied by coaching professionals, travel combined with courses on self-knowledge, resorts or spas for meditation, and other self-oriented activities, and promoting content that identifies the act of traveling as an opportunity to gain self-knowledge, for example.

\subsection{LITERATURE CONTRIBUTIONS}

Although most of the motives explored here have already been researched, this study took a concentrated approach in a few academically explored traveler profiles, focusing on motivations related specifically to people who love to travel and who are considered major stimulators and fomenters of tourism. From the perspective of consumer behavior and studies on personality and motivation, the research corroborates the further development of the $3 \mathrm{M}$ Model, in that it investigates a behavior not yet explored by the model and it proposes the addition of push and pull motives at different levels of the model.

\subsection{LIMITATIONS AND FUTURE RESEARCH}

The decision not to study the level of elementary traits of the $3 \mathrm{M}$ Model is a limitation of the study. It was carried out in an attempt to produce a streamlined questionnaire and avoid tiring respondents. However, the possibility to extensively analyze the relationships among elementary traits and other traits and motives studied was lost. A subsequent investigation could include elementary traits, to add greater detailed personality questions for travel lovers.

As this quantitative research did not differentiate between traveler profiles or the level of "career/amount of experience" (Pearce, 1988, 1991, 1993), a future study could perform a cluster analysis oriented toward an identification of travel orientation levels and the relationship between those levels and the act of travelling. Some people may have great travel orientation and have identified themselves with the motives, although they would not be considered frequent travelers. The presence of such clusters could provide different results for the analysis of the model, what can cause an unobserved heterogeneity, as mentioned by Hair et al. (2014b).

As the sample consisted mainly of women and people of higher income and schooling, it could affect the outcomes and reduce the power of generalization of the data, emphasizing the motivations that rich and educated women value the most and surpassing men's motivations. For this reason, future studies could include a more heterogeneous population, promoting a sample with a balanced quantity of men and women and a more varied range of income and schooling. In addition, because we only investigated Brazilians, further studies should replicate the scales used here to investigate people from other nationalities in a cross-cultural study. 


\section{ACKNOWLEDGEMENT}

\section{REFERENCES}

ABEP (Associação Brasileira de Empresas de Pesquisa). 2014. "Critério de Classificação Econômica Brasil.” http://www.abep.org/criterio-brasil (accessed April 2, 2014).

Abosag, I., and Farah, M. F. 2014. "The influence of religiously motivated consumer boycotts on brand image, loyalty and product judgment." European Journal of Marketing, 48 (11) 12: 2262 - 2283.

Bandeira-De-Mello, R. and Cunha, C. 2006. "Grounded Theory.” In Pesquisa Qualitativa em Organizações: Paradigmas, Estratégias e Métodos, edited by Godoi, C., Bandeira-De-Mello, R. and Silva, A. São Paulo: Ed. Saraiva.

Bardin, L. 2009. Análise de conteúdo. 5. ed. Lisboa: Edições 70.

Basso, K. 2008. "Personalidade e Lealdade: Uma Aplicação do Modelo Meta-Teórico de motivação e personalidade (3M)." Master's Thesis, Faculdade de Administração, Contabilidade e Economia, Pontifícia Universidade Católica do Rio Large do Sul, Porto Alegre.

Caber, M. and Albayrak, T. 2016. "Push or pull? Identifying rock climbing tourists' motivations." Tourism Management 55 (2016): $74-84$.

Carver, C. S. and Scheier, M. F. 1990. "Origins and functions of positive and negative affect: A control-process view.” Psychological Review, 97:19-35.

Chang, I., Liu, C. and Chen, K. 2014. "The push, pull and mooring effects in virtual migration for social networking sites". Info Systems Journal, 24: 323-346.

Chen, H., and Sasias, M. 2014. "Tourist Segmentation in Taiwan's Wineries: A cultural Perspective." Social Behavior and Personality, 42(2): 223-236.

Correia, A., Valle, P., and Moço, C. 2005. "Why people travel to exotic places." Paper presented at The Fourth CPTHL Symposium Consumer Psychology of Tourism, Hospitality, and Leisure Research, 18-21st July, Montreal, Canada.

Crompton, J. L. 1979. "Motivations for pleasure vacation.” Ann. Tourism. Res. 6: 408-424.

Dann, G. M. S. 1977. “Anomie, Ego-Enhancement and Tourism.” Annals Of Tourism Research, 4: 184-194.

Dias, R., and Cassar, M. 2005. Fundamentos do Marketing Turístico. Pearson Prentice Hall: São Paulo.

Fang, X., and Mowen, J. C. 2009. "Examining the trait and functional motive antecedents of four gambling activities: slot machines, skilled card games, sports betting, and promotional games." Journal of Consumer Marketing, 26: 121-131.

Festinger, L.1962. A theory of cognitive dissonance (Vol. 2). Stanford university press.

Fodness, D. 1994. "Measuring tourist motivation.” Annals of Tourism Research, 21 (3): 555-581.

Fontanella, B. J. B., Luchesi, B. M., Saidel, M. G. B., Ricas, J., Turato, E. R., and Melo, D. G. 2011. Amostragem em pesquisas qualitativas: proposta de procedimentos para constatar saturação teórica. Cad. Saúde Pública, Rio de Janeiro, 27(2): 389-394.

Fontanella, B. J. B., Ricas, J.,and Turato, E. R. 2008. "Amostragem por saturação em pesquisas qualitativas em saúde: contribuições teóricas." Cadernos de Saúde Pública. 24(1): 17-27.

Galloway, G. 2002. "Psychographic segmentation of park visitor markets: evidence for the utility of sensation seeking." Tourism Management, 23(6): 581-596.

Galloway, G., Mitchell, R.; Getz, D., Crouch, G., and Ong, Ben. 2008. "Sensation seeking and the prediction of attitudes and behaviours of wine tourists." Tourism Management, 29(5): 950-966.

Gauge.2014. "Além das faces do Facebook". São Paulo. htttp://www.gauge.com.br/alemdasfacesdofacebook/ completo.pdf (accessed December 10, 2016).

Gazley, A. and Watling, L. 2015. "Me, My Tourist-Self, and I: The Symbolic Consumption of Travel." Journal of Travel and Tourism Marketing, 32:639-655.

Hair, J. Black, W.C., Babin, B.J., Anderson, R.E. and Tathan, R.L. 2009. Análise Multivariada de Dados. 6th ed. Bookman, Porto Alegre.

Hair, J., Black, W.C., Babin, B.J, and Anderson, R.E. 2014b. Multivariate Data Analysis. 7th ed. Pearson, Harlow.

Hair, J., Hult, G.T.M., Ringle, C.M., and Sarstedt, M. 2014a. A Primer on Partial Least Squares Structural Equation Modeling (PLS-SEM). Sage, Thousand Oaks.

Holbrook, M. B., and Olney, T. J. 1995. "Romanticism nd wanderlust: An effect of personality on consumer preferences.” Psychology and Marketing, 12 (3): 207-222. 
BBR

16,1

85

Hung, K., and Petrick, J.F. 2011. "Why do you cruise? Exploring the motivations for taking cruise holidays, and the construction of a cruising motivation scale." Tourism Manage. 32 (2): 386-393.

Jang, S., and Wu, C.-M. E. 2006. "Seniors' travel motivation and the influential factors: an examination of Taiwanese seniors." Tourism Management, 27: 306-316.

Kim, J.H., and Ritchie, B.W. 2012. "Motivation-based typology: An empirical study of golf tourists.” Journal of Hospitality and Tourism Research, 36 (2): 251-280.

Kirkwood, J. 2009. "Motivational factors in a push-pull theory of entrepreneurship." Gender in Management: An International Journal, 24 (5): 346 - 364.

Lee, C., Lee, Y., and Wicks, B. E. 2004. "Segmentation of festival motivation by nationality and satisfaction." Tourism Management, 25: 61-70.

Lindstrom, M. 2012. Brand sense: Os segredos sensoriais por trás das coisas que compramos. Bookman, Porto Alegre.

Lundberg, D. E. 1990. The tourist business (6th ed.). New York, NY: Van Nostrand Reinhold.

Malhotra, N.K. 2001. Pesquisa de marketing: uma orientação aplicada. 3rd ed. Bookman, Porto Alegre.

Mckercher, B., Denizci-Guillet, B. and Ng, E. 2012. "Rethinking Loyalty." Annals of Tourism Research, 39(2): 708-734.

Middleton, V. T. C. 2001. Marketing in Travel and Tourism. $3^{\circ}$ ed. Oxford: Butterworth-Heinemann.

Monteiro, P.R.R. 2006. "Personalidade, Compra Compulsiva, Hábitos e Inovação em Moda: Uma aplicação do modelo 3M de motivação e personalidade." Master's Thesis, Centro de Pós-Graduação e Pesquisas em Administração, Universidade Federal de Minas Gerais, Belo Horizonte.

Montgomery, J. 2008. "The role that personality and motivation play in consumer behaviour: a case study on HSBC.” Business Intelligence Journal. July: 128-134

Moscardo, G. M., and Pearce, P. L. 1986. "Historical Theme Parks: An Australian Experience in Authenticity." Annals of Tourism Research, 13 (3): 467-794.

Mowen, J. C. 2000. The 3M model of motivation and personality: Theory and empirical applications to consumer behavior. Kluwer Academic Publishers, Boston.

Mowen, J. C.; Longoria, A.and Sallee, A. 2009. "Burning and cutting: Identifying the traits of individuals with an enduring propensity to tan and to undergo cosmetic surgery." Journal of Consumer Behaviour, 8: 238-251.

Mowen, J.C. and Minor, M.S. 2003. Comportamento do consumidor. Prentice Hall, São Paulo.

Mowen, J.C., and Sujan, H. 2005. "Volunteer behavior: A hierarchical model approach for investigating its trait and functional motive antecedents." J. Consum. Psychol. 15: 170-82.

Oliver, R.L. 1997. Satisfaction: a behavioral perspective on the consumer. New York: McGraw-Hill.

Ong, T.F., and Musa, G. 2012."Examining the influences of experience, personality and attitude on SCUBA divers' underwater behaviour: A structural equation model." Tourism Manage. 33 (6): 1521-1534.

Park, D.-B., and Yoon, Y.-S. 2009. "Segmentation by motivation in rural tourism: a Korean case study." Tourism Management, 30(1): 99-108.

Pearce, P. L.and Lee, U. 2015. "Developing the Travel Career Approach to Tourist Motivation." Journal of Travel Research, 43: 226-237.

Pearce, P. L., and Caltabiano, M. I. 1983. "Inferring travel motivation from traveller's experiences.” Journal of Travel Research, XXII: 16-20.

Pearce, P.L. 1988. The Ulysses factor: Evaluating visitors in tourist settings. Springer-Verlag, New York.

Pearce, P.L. 1991. "Dreamworld: A report on public reactions to Dreamworld and proposed developments at Dreamworld." A report to Ernst and Young on behalf of the IOOF in conjunction with Brian Dermott and Associates. Department of Tourism, James Cook University, Townsville.

Pearce, P.L. 1993. "Fundamentals of tourist motivation." In Tourism Research: Critiques and Challenges, edited by Pearce, D. and Butler, R., 85-105. Routledge and Kegan Paul, London.

Pearce, P.L., and Lee, U.I. 2005. "Developing the travel career approach to tourist motivation." Journal of Travel Research, 43: 226-237.

Pieske, A. E. 2008. "Participaçăo do consumidor no desenvolvimento do sistema Linux : aplicaçăo do modelo 3M de Mowen.” Master's Thesis, Departamento de Ciências Administrativas, Universidade Federal do Paraná, Paraná.

Pirsig, R. M. 1974. Zen and the art of motorcycle maintenance: An inquiry into values. New York: Bantam Books.

Plog, S. C. 1987. "Understanding psychographics in tourism research". In Travel, tourism, and hospitality research: A handbook for managers and researchers, edited by Ritchie, J. R. and Goeldner, R., 203-221. New York, NY: Wiley. 
Radius Kommunikation 2016. “Momondo: International PR Survey 2016.” http://radiuskommunikation.dk/ case/momondo-international-pr-survey/?lang=en (accessed October 12, 2016).

Schneider, P.P. and Vogt, C.A. 2012. "Applying the 3M Model of Personality and Motivation to Adventure Travelers." Journal of Travel Research, 51, 6: 704-16.

Scott, K.and Mowen, J. C. 2007. "Travelers and their traits: a hierarchical model approach". Journal of Consumer Behaviour, 6: 146-157.

Skift. 2015. "Megatrends defining travel in 2015." http://skift.com/2015/01/13/new-skift-magazine-megatrends-defining-travel-in-2015/ (accessed June 15, 2015).

Sun, T.and Wu, G. 2011. "Traits, Predictors, and Consequences of Facebook Self-Presentation." Social Science Computer Review, 30 (4): 419-433.

Swarbrooke, J., and Horner, S. 2002. O comportamento do consumidor no turismo. Aleph, São Paulo.

Swarbrooke, J., Beard, C., Leckie, S., and Pomfret, G. 2011. Adventure Tourism: The new frontier. New York: Routledge.

UNWTO. 2013. "World Tourism Organization. Tourism Highlights." http://dtxtq4w60xqpw.cloudfront.net/ sites/all/files/pdf/unwto highlights 13 en_lr_0.pdf (accessed February 5, 2014).

UNWTO. 2016. "World Tourism Organization. Tourism Highlights." http://www.e-unwto.org/doi/ pdf/10.18111/9789284418145 (accessed February 6, 2016).

Uysal, M., and Hagan, L. R. 1993. "Motivation of pleasure to travel and tourism." In M. A. Khan, M. D. Olsen, and T. Var (Eds.), VNR's encyclopedia of hospitality and tourism (pp. 798-810). New York: Van Nostrand Reinhold.

Voigt, C., Brown, G., and Howat, G. 2011. "Wellness tourists: in search of transformation.” Tourism Review, $66,1 / 2,16-30$.

World Economic Forum. 2017. “The Travel and Tourism Competitiveness Report 2017." https://www.weforum.org/reports/the-travel-tourism-competitiveness-report-2017 (accessed October 6, 2017).

Yoon,Y. and Uysal, M. 2005. "An examination of the effects of motivation and satisfaction on destination loyalty: a structural model." Tourism Management, 26: 45-56. 